CuPAUAM. 15-1988

\title{
EL ASENTAMIENTO HUMANO COMO INDICADOR DEL CAMBIO CULTURAL. EL CASO DE LA REGION VALENCIANA
}

\author{
Manuel Corral Cañón † \\ Isabel Rubio de Miguel (Dpto. de Preh. y Arq. UAM)
}

\begin{abstract}
Resumen
El punto de partida de este artículo es el estudio del cambio cultural que se traduce en la aparición de sociedades cada vez más complejas. Se toma como base un aspecto: el del asentamiento humano en el área valenciana, ya que las sistematizaciones y estratigrafías de la misma permiten establecer una secuencia más firme. El estudio se inicia con los escasos datos del Epipaleolítico y concluye con la aparición de los cambios que anuncian ya la Edad del Bronce. Se constata la dualidad del hábitat, en cueva y al aire libre, prácticamente desde el inicio de la secuencia, un desplazamiento al asentimiento en superficie, favorecido por los factores ambientales, en el Eneolítico y la construcción de dispositivos de defensa en la Edad del Bronce. Se discuten las posibles causas del cambio y los tipos de sociedad de los que son reflejo.
\end{abstract}

\section{SUMMARY}

The main subject of this article is the study of cultural changes revealed in the origins of more complex societies. Human settlement in Valencian area is taken as the basic aspect because sistematizations and stratigraphies allow to establish there a reliable cultural sequence. The study begins with the scarce epipaleolithic data and ends with the start of changes announcing Bronze Age. Duality in habitat (caves and villages) is proved practically from the beginning of the sequence, as it is a shift to the surface settlements in the Eneolithic, favoured by environmental conditions, and the construction of defensive walls in Bronze Age. Possible causes are discussed and also different kind of societies they may reflect.

Parece adecuado comenzar precisando cuáles son los límites dentro de los que se sitúa el contenido el presente artículo y, sobre todo, los términos del título mismo que, como casi siempre sucede al tratar de poner nombre a procesos del cambio cultural de por sí comple- 
jos, puede no ser suficientemente clarificador. La idea inicial consistía en abordar el estudio del cambio que supone el paso de una sociedad agrícola (o incluso anterior si hubiera sido posible), a una más compleja asociada tradicionalmente a la aparición de la metalurgia, aún cuando esta última relación se haya revelado como no válida al menos de forma generalizada, a través del registro arqueológico de alguna zona distinta a la del S.E. peninsular. En una palabra, tratábamos de hacer objeto de nuestro estudio el nacimiento de una sociedad supuestamente jerarquizada, intentando determinar el cuándo y el cómo de su aparición. Nos pareció un tema interesante en sí mismo y, por otra parte, pensamos en la utilidad de su investigación en un área diferente a la señalada, porque ésta, la S.E., ya había sido objeto de estudio incluso por parte de la literatura internacional (Gilman y Thornes, 1985; Gilman, 1987 a y 1987 b y Vicent, 1989) y, también, porque así podrían irse estableciendo otros términos de comparación sobre el mismo proceso dentro de la Península Ibérica.

Tratando de determinar la zona de estudio llegamos a la conclusión de que el País valenciano poseía datos aparentemente suficientes, extremadamente sugerentes además, así como estratigrafías y sistematizaciones fiables como para poder trazar una secuencia que permitiera intentar la investigación. No obstante, los objetivos iniciales de la misma se han visto reducidos debido a dolorosas circunstancias (1) y, así, se ha centrado exclusivamente en el asentamiento propiamente dicho, considerado como expresión de los cambios que nos proponíamos estudiar, aún cuando evidentemente se contemplen datos de otra índole.

Se ha hecho alusión en múltiples ocasiones a este tipo de sociedades denominándolas jerarquizadas o estratificadas, complejas en definitiva en cuanto a las relaciones sociales que en ellas se establecen, con un trasfondo económico y social de evidente relieve que las condiciona. La bibliografía sobre el tema publicada en los últimos años es realmente abundante y, de manera particular, la que se refiere a su nacimiento, causas e, incluso, desaparición en casos más concretos. Por tanto, baste la referencia, ni mucho menos exhaustiva, a determinadas obras, algunas ya clásicas, donde se tratan los aspectos anteriormente señalados y las diversas hipótesis sobre su orígen [Braidwood y Willey (Eds.), 1962; Brumfiel y Earle (Eds.), 1987; Carneiro, 1970; Fried, 1967; Friedman y Rowlands, 1978; Godelier, 1971; Gordon Childe, 1954 y 1976; Manzanilla (Ed.), 1987; Mc Adams, 1966; Sabloff y Lamberg-Karlowsky (Eds.), 1974; Service, 1984; Tainter, 1988; Ucko, Tringham y Dimbleby (Eds.), 1972; Wittfogel, 1966, etc.].

Naturalmente, dentro de esta complejidad existen grados diferentes que responden a otros tantos tipos de sociedad. Así por ejemplo, se denominó en algún momento a estas sociedades como urbanas (no urbanizadas), considerando que la ciudad era la expresión visible de la ocupación del espacio por parte de esos grupos humanos. Si ello ha podido ser así en los focos más antiguos, se ha puesto de manifiesto que no en todos los ámbitos sucede lo mismo,

(1) El fallecimiento en accidente automovilístico del amigo y colega M. Corral Cañón, determinó, evidentemente, que la redacción definitiva del artículo, recayera exclusivamente sobre uno de nosotros, empleando los datos ya recopilados y elaborados hasta ese momento. Por tanto, soy única responsable de la misma y de los posibles errores que pudieran existir en ella. Por razones obvias no me he adentrado más en cuestiones que hubieran requerido una ulterior discusión, limitándome a incorporar algún dato aparecido con posterioridad y que resultaba fundamental. Sirvan pues estas páginas como recuerdo al buen amigo y colega tempranamente desaparecido. 
razón por la que se han acuñado expresiones como «urbanismo sin ciudades». De este modo, se ha trasladado la problemática desde un terreno puramente material, por así decirlo, al de la economía y las relaciones sociales, aún cuando todos ellos estuvieran detrás del primero. No en vano, conceptos como los señalados más arriba se consideraban asimismo sinónimos de civilización. Sin extendernos más en estos aspectos, cabría señalar que los patrones de asentamiento son uno de los rasgos más llamativos en el estudio del tema (y no sólo de éste), que evidencian además todo el entramado económico y social existente en cada momento. Los cambios que se operan en ellos, las motivaciones de las diversas distribuciones espaciales y las relaciones entre las distintas aglomeraciones, jerárquicas o no, o las diferencias de tamaño señalan lo antedicho. Por tanto, bien pueden servir como base y punto de partida a estudios sobre el cambio cultural que se opera con la aparición de sociedades más complejas.

Es pues en este sentido en el que enfocamos este artículo. Por tanto, cualquier modificación en el asentamiento y sus posibles motivaciones será el objeto de nuestro estudio.

La pretensión inicial de contemplar este proceso desde etapas anteriores quedó restringida al tropezarnos con una enorme escasez de datos por lo que respecta al Epipaleolítico, magníficamente estudiado desde el punto de vista de la industria lítica, por ejemplo (Fortea, 1973). Da la sensación de que los yacimientos al aire libre son escaso en este momento, yacimientos como el de Pinar de Tarruella (Villena, Alicante), perteneciente al complejo microlaminar (Fortea, 1973, 155), situado precisamente en un fondo de arenas lacustres correspondientes a la amplia laguna de Villena y cerca del Arenal de la Virgen, nos permite, junto con otros (los de la albufera de Anna o Ferreginal de la Font Major), atestiguar tal tipo de hábitat paralelo al predominante en cueva que ya lo era de forma prácticamente absoluta y según los datos que poseemos en el Paleolítico superior.

La problemática del tipo de hábitat como reflejo de una determinada sociedad o actividad, aunque referido exclusivamente al Neolítico peninsular, ya había sido abordado por uno de nosotros en un artículo en el que, dadas las limitaciones de espacio, no había lugar más que para esbozar y enumerar determinadas particularidades y aspectos muy concretos (Rubio, 1984-1985). Básicamente se señalaba en él cómo la dualidad de asentamientos (en cueva y al aire libre), era clara en todo el Neolítico peninsular (más de sesenta poblados ya en estos momentos) y que desde luego, tal dualidad parecía poderse suponer con anterioridad. Todo ello venía a anular, en cierto modo, la expresión «cultura de las cuevas» referida al primer Neolítico peninsular, así como también la contraposición entre hábitat en cueva/economía pastoril o cazadora y hábitat al aire libre/economía productora. Por otra parte, el primero parecía proporcionar secuencias más prolongadas y testimonios más numerosos sobre actividades económicas, mientras que en el segundo eran escasos, siendo los mismos yacimientos de carácter efímero, prácticamente sin estructuras determinables y, salvo excepciones, sin estratigrafías de ningún género. Evidentemente, dificultades de conservación de los mismos podrían matizar este panorama, no sabemos en qué medida.

En cualquier caso, quedaba claro que prácticamente no podía señalarse ningún dato sobre las estructuras mismas, salvo en el caso de El Tirao del que conocemos la planta y la sección (Mesado, 1970), o la referencia a los vestigios de barro con improntas de cañas y troncos en Casa de Lara (Soler, 1976). La cronología de los poblados de la provincia de Castellón 
estaba y está aún poco clara. Se reparten tanto por la zona litoral donde se da por supuesta una actividad recolectora de gramíneas (Olaria, 1980, 34-35), como por el interior. Otros situados en las provincias de Alicante o Valencia se hallan en la proximidad de lagunas actuales (albufera de Anna), o ya desecadas (Arenal de la Virgen o Casa de Lara) (Rubio, 1984-1985, 156). No obstante, es preçiso reconocer que en esta etapa y en el área valenciana el hábitat en cueva es el predominante, por lo que se reseñan más bien las particularidades del de superficie por lo que representa en cuanto a novedad y diversidad. Remito al citado artículo para más detalles, ya en el mismo se recogen las opiniones de otros autores sobre el asentamiento neolítico (Rubio, 1984-1985).

Más tarde, Martí $(1985,67)$ señalaba que la utilización de las cuevas en una sociedad agrícola supone un límite a la cuantía en el crecimiento de los grupos humanos. ¿Habría que pensar entonces que se trata de momentos en que éste es más bien bajo? ¿Podría deberse en parte este predominio de las cuevas a una laguna en la investigación o a la pérdida de información ya señalada?

Recientemente J. Bernabéu $(1988,154)$ ha indicado la existencia de más de una treintena de poblados en las comarcas al sur del río Júcar que habría que añadir a los ya citados, conocidos unos y otros por recogidas superficiales que vienen a demostrar lo esencial de las prospecciones sistemáticas.

Este mismo autor indica como, a excepción de la Ereta del Predregal, ningún poblado ha sido excavado en extensión, si bien los materiales permiten establecer una cronología de finales del $\mathrm{IV}^{\circ}$ milenio o principios del $\mathrm{III}^{\circ}$, perdurando algunos durante la etapa campaniforme (Bernabéu, 1988, 154). Se trataría del Neolítico II (N II) de su clasificación, caracterizado por formas abiertas en las cerámicas, puntas de flecha y uso del retoque plano en la industria lítica, reducción de la industria ósea y un extraordinario desarrollo de los elementos de adorno. El grueso de todo lo señalado se vuelve a encontrar en el Eneolítico precampaniforme (ca. 2.500/400-2.220/2.100 a. C.), indicando un claro continuismo.

Desde el punto de vista estratigráfico el contacto Neolítico/Eneolítico podemos hallarlo en dos lugares: en la Cova de les Cendres (V y VI) y en la Ereta del Pedregal (I), en el momento ya citado como N II (3.500/400-2.500/400 a. C.), así como en los niveles III a I de Or (Bernabéu, 1988, 151). Con todo, cabría desglosar estos horizontes de la siguiente manera (Bernabéu, 1988, 152-153): un N IIA con cerámicas esgrafiadas y peinadas (equivalente a los niveles V de les Cendres y III de Or), y un N IIB donde desaparece este tipo decorativo y se documentan los triángulos incisos rellenos con impresiones de punzón (IV de les Cendres, II-I de Or y I de Ereta). Lo propio de este momento sería la disgregación de los grupos culturales del Neolítico y la generalización del poblado al aire libre.

Para Bernabéu el Eneolítico valenciano sería más bien una fase terminal del Neolítico, perdurando hasta el horizonte de Transición (H. C. T.), momento en el que este fondo cultural evoluciona rápidamente hacia formas próximas a la cultura del Bronce valenciano. La metalurgia no se encuentra en esta región hasta Ereta III, por ejemplo, dentro ya del H. C. T. Estos poblados son pues anteriores a la aparición del recinto amurallado que aquí se encuentra a partir del campaniforme y que se desarrolla ampliamente en el Bronce valenciano. 
Se hallarían ahora, en el N II, las primeras necróplis cerca de los poblados: cuevas naturales con enterramiento múltiple, como en el caso de Jovades-Benatarre. Tal como el anteriormente citado autor señala y nosotros mismos hemos constatado (Rubio, 1982), el enterramiento en cueva existe desde el Neolítico, si bien en su variante individual. Por ello, los nuevos hallazgos, asociados a materiales del $\mathrm{IV}^{\circ}$ milenio o incluso finales del mismo, revisten particular interés, aún cuando su generalización no se produzca hasta el $\mathrm{III}^{\circ}$, perdurando hasta la Edad del Bronce. Es evidente que estos poblados se encuentran al menos en un momento de transición al Eneolítico, si bien puede pensarse que, dadas sus características, podrían situarse ya en este período. Evidentemente no es así desde el punto de vista de la metalurgia, pero difieren de lo precedente en cuanto a materiales, forma de asentamiento y de enterramiento, aspecto éste que nos llevaría a paralelizarlos con el megalitismo existente en otras áreas, únicamente en cuanto al rito, y ausente aquí hasta en su variante de cueva artificial presente por ejemplo en la provincia de Murcia.

Refiriéndose al valle medio del río Alcoy, J. Bernabéu (1988, 155-156) precisa que, en el N II, crece el número, dispersión y tamaño de los yacimientos, indicando una concentración demográfica. No obstante, señala que esta ocupación pudo no ser sincrónica. Tal concentración no concordaría con la supuesta agricultura de rozas, sino que haría pensar en una modificación de la tecnología agrícola para acortar los períodos de barbecho y el número de individuos/cantidad de tierra para su mantenimiento. Esta modificación pudo ser el arado de madera, de reja vertical y sin pié, los animales de tracción y la utilización del agua a pequeña escala (Bernabéu, 1988, 156), como podría indicar su situación inmediatamente sobre la actual llanura de inundación del río.

Para el mismo autor (Bernabéu, 1986, 9-14), justo tras el final del Neólitico medio con cerámicas incisas e impresas no cardiales, hay un retroceso en la ocupación de las cuevas: Fosca, Sarsa u Or y sólo les Cendres mantiene esta intensidad, debido al aprovechamiento de recursos marinos. Sin embargo, estas cuevas proporcionan las secuencias más amplias e importantes y no sólo las citadas. La Cova d'en Pardo abarca en su estratigrafía desde un Epipaleolítico microlaminar hasta un enterramiento colectivo, por debajo del que se constata la aparición de cerámicas esgrafiadas (Muñoz, 1985, 87).

No parece que se evidencie claramente una debilidad de ocupación en las cuevas, sobre todo porque haría falta un número mayor de estratigrafías claras como las de Or y Cendres para determinar con certeza si se trata de una tendencia generalizada. Por otra parte, este tipo de hábitat perdura hasta entrado en Eneolítico. Por lo mismo no parece haber habido un cambio automático de las misma cuevas de hábitat a cuevas de enterramiento. En todo caso, no da la sensación de que se hayan utilizado las mismas, abandonadas o no, salvo en algún caso concreto (la citada de El Pardo).

Pero veamos cuáles han sido los trabajos que han permitido ir configurando los diversos tipos de asentamientos eneolíticos valencianos.

A partir del estudio de Tarradell (1959, 86-91), comienzan a perfilarse las características que permiten identificar los poblados de este momento: en zonas llanas y no en altura como había propuesto Visedo (1925, 173-176), ya que esta situación parece más propia de la Edad del Bronce o de la transición (H.C.T.). Se determinan dos grupos: 
1. Los formados por cabañas como la Ereta del Pedregal y Casa de Lara (Tarradell, 1959, 88-89).

2. Los caracterizados por silos como los de Bélgida (Beniprí, Atarcó, Caseta del General y Alfogás) (Tarradell, 1959, 89), Elche (Figuera Reona) y Villarreal (Villa Filomena) (Tarradell, 1959, 90).

En 1961 el mismo autor (Tarradell, 1961, 107) incluye como dudoso el la Comba (Benicássim, Castellón). Asimismo, plantea la posibilidad, hipotética en base a los datos disponibles, de que algunos de los poblados de altura (tipo Bronce valenciano) hayan iniciado su vida en la primera fase de los Metales (Tarradell, 1961, 107).

Martí certifica posteriormente (1980, 134-136) esta última posibilidad, distinguiendo tres tipos de asentimientos al aire libre:

1. Poblados en llano: Ereta del Pedregal, Beniprí, el nivel inferior de El Tirao (Burriana, Castellón), Les Santes (Cabanes, Castellón) y Font Mahiques (Cuatretonda).

2. Los silos de Bélgida (Alfogás, Caseta del General y Atarcó), Villarreal (Villa Filomena), Albaida (Sifó de les Fanegaes), Castellón de Rugat (Tabaque), en Valencia y Cocentaina (Jovades) en Alicante.

3. Poblados en alturas medias o elevadas que perviven en la etapa siguiente: Peñón de la Zorra, Puntal de Carniceros en Alicante, la Ereta de Castellar en Castellón y el Castillejo de los Moros, en Valencia (Tarradell, 1980, 136).

Junto a éstos continuará el hábitat en cueva (Martí, 1980, 132), como se ve en la Cova de l'Or, o la Cova d'en Pardo, en la provincia de Alicante.

Ya en 1959 Arribas (103-105) opinaba que otros poblados que podrían encuadrarse en el Calcolítico o la transición al Bronce eran Mas de Menente, Mola Alta de Serelles, Ull del Moro (Alcoy), la Barsella (Torremanzanas), en Alicante y Peña de la Dueña (Teresa), en Castellón.

La aportación más importante de los últimos tiempos ha sido el hallazgo de Les Moreres (Crevillente, Alicante), en el que lo más destacado es la aparición de estructuras de muros rectos desde la fase IV (González Prats, 1982, 7-8).

Ana M. ${ }^{a}$ Muñoz $(1985,85)$ por su parte señalaba que el Eneolítico del País valenciano se caracterizaba, entre otras cosas, por el ritual sepulcral múltiple, por la generalización de la instalación en poblados al aire libre con el paulatino abandono del hábitat en cueva y por materiales arqueológicos muy concretos que iban desde las cerámicas lisas, pasando por las puntas de flecha de retoque bifacial o variados elementos ornamentales y representaciones de ídolos en estilizaciones antropomorfas y materiales muy diversos. La metalurgia, en general, era escasa y poco incidente, según constataba la misma autora.

Resulta evidente que se trata prácticamente de los mismos rasgos atribuidos por J. Bernabéu al N II. Por lo demás A. M. ${ }^{a}$ Muñoz afirma que el campaniforme no podría incluirse en el Eneolítico. Para ella la variación que experimenta el hábitat en el momento de aparición de dicho fenómeno sería la instalación de los poblados al aire libre formando aglomeraciones pequeñas o amplias que, a veces, parecen ocupaciones estacionales, o bien la reutilización de poblados eneolíticos fortificados (Muñoz, 1985, 86). 
Sin embargo, justamente el H.C.T. podría ser considerado como el auténtico Eneolítico a juicio de Bernabéu $(1986,14)$, mientras que la etapa anterior sería un Neolítico final cronológicamente paralelo a las primeras culturas de la Edad del Cobre del S. E.. Si atendemos al criterio de aparición de la metalúrgia parece más ajustada esta opinión. De todos modos no es nuestra intención entrar en polémicas sobre terminología o incluso poner en primer plano discusiones sobre cronologías, aunque naturalmente deban ser tenidas en cuenta, sino constatar los cambios culturales y sociales que se ponen de manifiesto en esta secuencia concreta. No obstante, pueden servir como hitos en las etapas más avanzadas de la misma la aparición de la metalúrgia, del campaniforme o del poblado fortificado, asociado este último a la Edad del Bronce, junto con otros aspectos como es lógico.

Aborda también A. M. ${ }^{a}$ Muñoz la cuestión de la no aparición de construcciones megalíticas que ella atribuye a una organización social propia de grupos metalúrgicos. Lo cierto es que en el área valenciana no están presentes ni siquiera las cuevas artificiales. Sin embargo el megatilismo no se asocia en el resto de las regiones europeas y aún en algunas peninsulares forzosamente a sociedades de este tipo, documentándose su origen en grupos neolíticos, por lo que la ausencia de construcciones megalíticas habrá que buscarla en otras causas.

Recientemente, J. M. Vicent en su tesis doctoral inédita (1989, 59-60), haciéndose eco de estas cuestiones, concluye que el cambio que se opera en el Calcolítico peninsular respecto al hábitat no es tanto la sustitución de la cueva por el hábitat al aire libre, sino la utilización de la primera como enterramiento y el paso de lo que él denomina campamento a la aldea calcolítica y al poblado de larga ocupación con estructuras permanentes, con la consiguiente inversión de energía, matices reveladores de la estructura social y económica existente. Sus observaciones no se refieren exclusivamente al País valenciano en todo caso.

Después de esta breve revisión de las distintas opiniones existentes sobre los cambios producidos en el hábitat incluimos a continuación una relación, que no será seguramente exhaustiva, de los poblados hallados en el País valenciano. Por razones de diversa índole nos hemos detenido en los eneolíticos. En algunos casos, la atribución cultural y aún la funcional resulta dudosa y, por tanto, se hará referencia a ello en cada yacimiento concreto para no repetir su inclusión en los dos apartados del catálogo, aunque sí se haga en los dos mapas (Figuras 1 y 2). La numeración que sigue a cada poblado corresponde a la que tiene en el mapa en el que se incluye.

Los pertenecientes al neolítico lo están en el de la Figura 1 y son los que se relacionan a continuación:

Les Santes o Roqueral de Les Santes (Cabanes, Castellón) (1): se halla en el área serrana prelitoral, en la margen de un curso de agua escaso e intermitente, al pié de un acantilado con oquedades y abrigos. Estaba constituido por lechos de cenizas calificados corno fondos de cabaña con restos arqueológicos (Esteve, 1944). Dichos restos, entre los que figura una punta de flecha de tipo cruciforme, llevarían según C. Olaria al último tercio del $\mathrm{IV}^{\circ}$ milenio e inicios del $\mathrm{III}^{\circ}$ (Olaria, 1980, 51-55).

Pla de Pitja (Cabanes, Castellón) (2): Los hallazgos son útiles atípicos que no permiten su adscripción a un contexto neolítico con seguridad (Olaria, 1980, 37). 


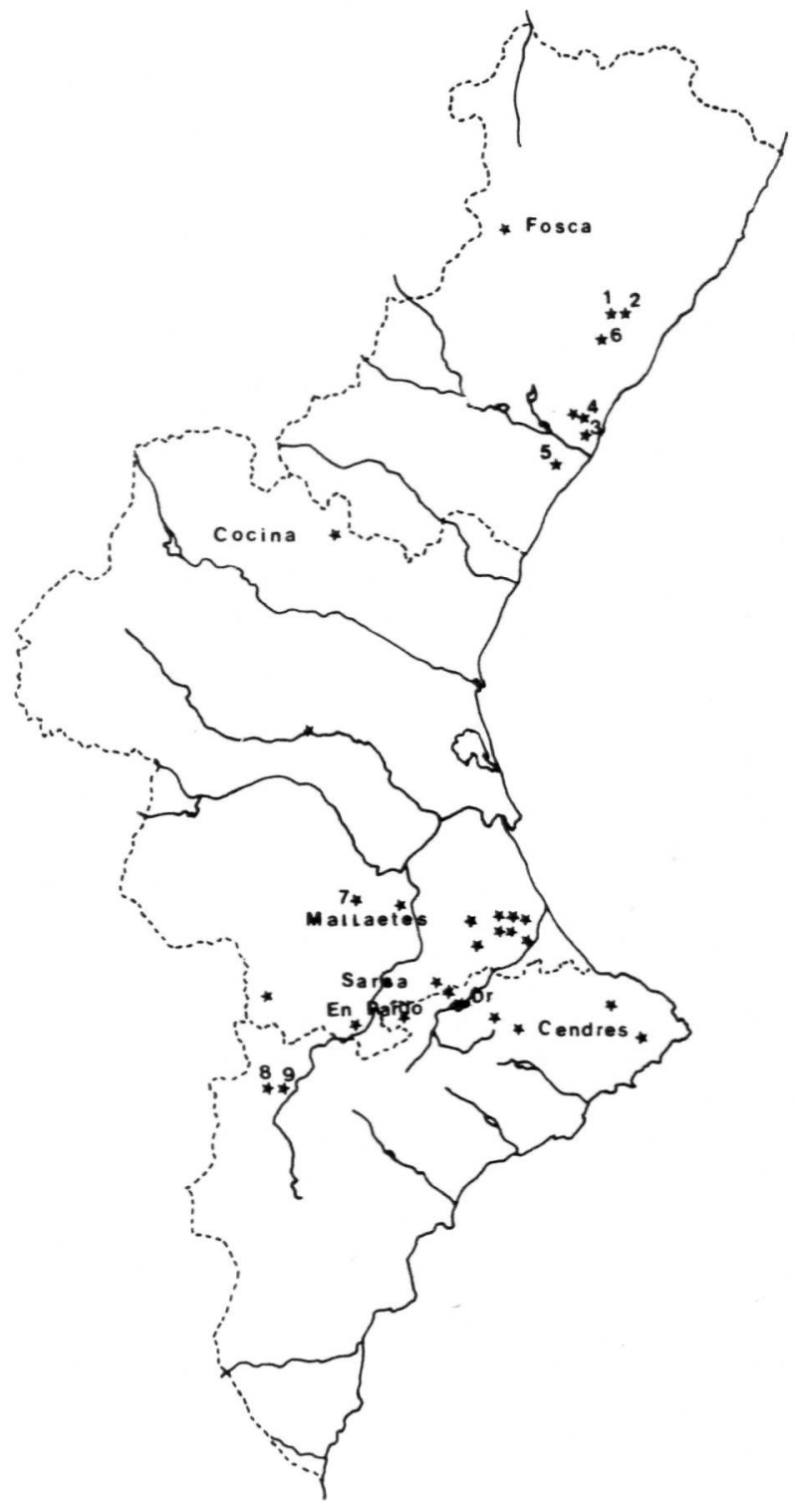

$\frac{\text { Esc. } 1: 1.500 .000}{153045 \mathrm{~km}}$

FIG. 1. - Poblados y cuevas neolíticos. Poblados: 1. Les Santes; 2. Pla de la Pitja; 3. Playa del Pinar; 4. Salandó; 5. El Tirao; 6. Corral Blanc; 7. Albufera de Anna; 8. Arenal de la Virgen; 9. Casa de Lara. Las cuevas no están numeradas indicándose únicamente el nombre de las más destacadas. 


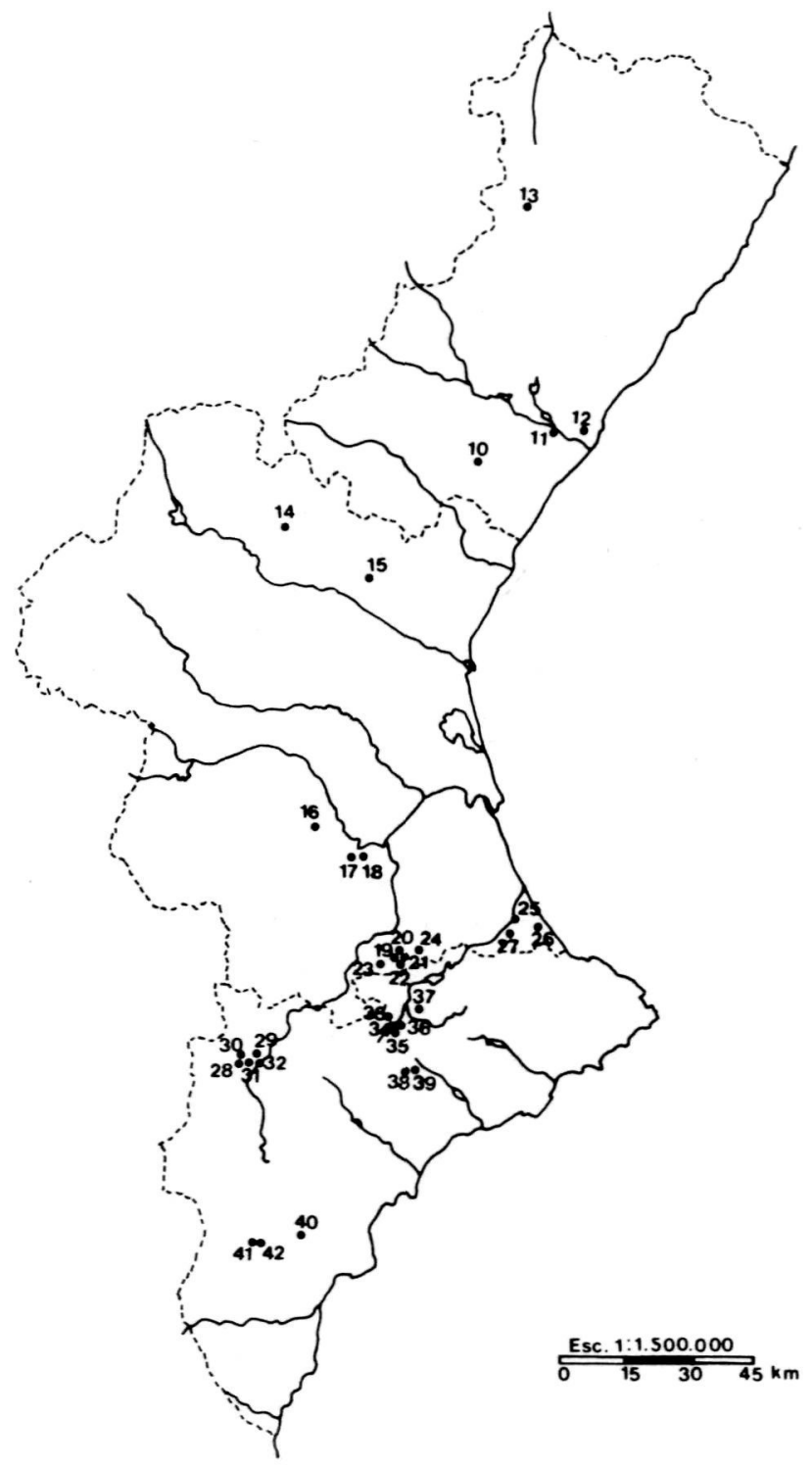

FIG. 2 - Poblados calcolíticos: 10. La Llometa del Fondo; 11. Villa Filomena; 12. La Comba; 13. Ereta del Castellar; 14. Castillejo de los Moros; 15. Puntal de la Rambla Castellarda o Mas del Jutge; 16. Ereta del Pedregal; 17. El Rincón; 18. La Muela; 19. Beniprí; 20. Atarcó; 21. Alfogás; 22. Caseta del General; 23. Sifó de les Fanegaes; 24. Tabaque; 25. Els Bancalets; 26. Camp de San Antoni; 27. La Horteta o Casa Fosca; 28. La Macolla; 29. Casa de Lara; 30. Arenal de la Virgen; 31. Puntal de Carniceros; 32. Peñón de la Zorra; 33. La Pastoreta; 34. Mola Alta de Serelles; 35. Mas de Menente; 36. Ull del Moro; 37. Les Jovades; 38. El Planet; 39. La Barsella; 40. Figuera Reona; 41. La Fonteta del Sarso; 42. Les Moreres. 
Playa del Pinar (Grao de Castelló) (3): se conoce exclusivamente por noticias sobre los materiales y estructuras, dado que nunca fué publicado (Olaria, 1980, 37).

Salandó (Benicássim, Castellón) (4): se encuentra ubicado en el área de pié de monte. Las industrias líticas halladas permiten encuadrarlo en una fase meso-neolítica (Olaria, 1980, 37).

El Tirao (Burriana, Castellón) (5): se halla en el área litoral llana, en la margen izquierda del río Anna o río Seco. Proporcionó una estratigrafía aproximada y cinco fondos de hogares en el nivel neolítico de los cuales sólo el C pudo ser estudiado, si bien el D contenía materiales arqueológicos (Mesado, 1970).

Corral Blanc (La Pobla Tornesa, Castellón) (6): situado en el área serrana prelitoral, reúne las mismas condiciones y características de Salandó (Olaria, 1980, 37).

Podrían citarse hallazgos se superficie de esta misma provincia, como el de Villarreal (una vasija conteniendo unas dos mil cuentas de collar) (Olaria, 1988, 116), o el enterramiento de Camí de la Costa (Olaria, 1988, 112) único hasta el momento, pero evidentemente sus características y función los apartan en principio de este trabajo.

Albufera de Anna (Valencia) (7): tal como su nombre indica se halla en las proximidades de la laguna actual. Se trata de dos yacimientos, situado uno a la orilla, perteneciente al Mesolítico I, con una cronología aproximada entre el 12.000 y el 9.500 a. C., y otro en el interior. En este último se han podido determinar dos fases: una del Mesolítico III, siempre según Aparicio (1975), con final hacia el 5.500 a. C. y otra con cerámica que el mismo autor clasifica como protoneolítico, anterior a la fase con cerámica cardial.

Arenal de la Virgen (Villena, Alicante) (8): J. Fortea lo incluye al igual que el siguiente en el complejo geométrico (Fortea, 1972, 377-383). Se encuentra situado sobre arenas, a orillas de la antigua laguna de Villena. Además del material lítico proporcionó cerámicas cardiales en perfecto estado de conservación (Soler, 1976, 32-35).

Casa de Lara (Villena, Alicante) (9): según Fortea (1973, 383-391) se paralelizaría con Cocina III o IV y tendría una posición terminal dentro del geometrismo epipaleolítico. En esta caso, se sabe que las viviendas parecen haber sido construidas con barro, ya que se conservan las improntas de los troncos y cañas de un supuesto armazón. Su situación exacta se localiza sobre las arenas, a orillas de un marjal, defendido a poniente por una colina utilizada para los enterramientos, a unos $25 \mathrm{Km}$. al W. de la cueva de la Sarsa. Además de la cerámica, cardial entre otras técnicas decorativas, se conserva un elevado número de piezas de sílex, destacando las puntas de flechas (las triangulares de aletas y pedúnculo fundamentalmente). Hay asimismo algún elemento de metal.

La atribución cronológica de estos dos últimos yacimientos es múltiple a causa de las características de sus materiales, por lo que deberán ser considerados igualmente dentro del apartado dedicado a los yacimientos eneolíticos.

Los pertenecientes al Eneolítico están reflejados en el mapa de la Figura 2. Para esta parte del catálogo se ha utilizado fundamentalmente la recopilación llevada a cabo por M. Corral. Se ha preferido clasificar dichos yacimientos siguiendo los tres tipos ya señalados por Martí (1980, 134-136). 


\section{A. Poblados en llano}

La Llometa del Fondo (Artana, Castellón) (10): Se hallaba en una suave loma de cumbre plana, quizá rodeada por una muralla defensiva (Tarradell, 1969, 14-15 y Aparicio, Martínez y San Valero, 1977, 49).

Ereta del Pedregal (Navarrés, Valencia) (16): según Fletcher (1961, 79-80) este poblado ocupa un pequeño altozano, de unas 16 Has. de extensión, sobre el nivel de la amplia depresión del terreno, posible lecho del lago. Posteriormente se fechó el nivel inferiór en un momento incierto entre el Neolítico final y el Calcolítico pleno, señalándose en la publicación (Pla y Martí, 1983, 239-240) la existencia de conjuntos de piedras de mediano y gran tamaño, con fragmentos de barro cocido, pero sin ulteriores explicaciones sobre la forma de las estructuras que delimitarían. Más recientemente, Ereta I se ha atribuido a un Neolítico final o Neolítico IIb (Bernabéu, 1986, 10 y 1988, 151), con puntas de flecha de sílex de todos los tipo que se intensifican luego en Ereta II (Calcolítico pleno), así como retoque plano en el trabajo del sílex y formas cerámicas más planas y abiertas (platos y fuentes), entre otras, que representarán asimismo una evolución en el momento siguiente.

No se conoce tampoco la forma de las estructuras de Ereta II, si bien se sabe que este nivel se compone de pavimentos entre fragmentos de muro, con las caras formadas por lajas hincadas verticalmente y rellenas de piedras y barro (Pla y Martí, 1983, 240).

El nivel III proporcionó los primeros vestigios de metalúrgia, situándose cronológicamente en la transición a la Edad del Bronce. Supone la aparición de un muro de piedras en hiladas regulares que, por su situación, se dice pudieran corresponder a la muralla del poblado (Pla y Martí, 1983, 240). No sabemos si ese muro es el mismo que como «calzado» señala Fletcher (Fletcher, 1961, fig. 2), como límite máximo del poblado.

Nada se nos indica acerca de las características constructivas y la organización del nivel IV que corre paralelo a los momentos iniciales del Bronce valenciano.

Beniprí (Bélgida, Valencia) (19): Este asentamiento que Martí (1980, 135-136) considera de características semejantes al anterior, sólo ha proporcionado un «lecho de piedras sueltas y desiguales» (Jornet, 1928, 87). Entre sus materiales destaca un vaso campaniforme (Jornet, 1928, 96).

La Macolla (Villena, Alicante) (28): Aunque con dudas, ya que los datos conocidos se refieren exclusivamente a materiales de superficie, es probable que este poblado situado en la margen derecha del Vinalopó, pertenezca a este grupo. Se puede calcular su extensión en $1 \mathrm{Ha}$. Soler (1981, 30-31) señala su semejanza con los otros poblados de la laguna de Villena en la elección del hábitat y su disparidad por lo que se refiere a los materiales, ya que faltan los geométricos y las cerámicas cardiales. Están presentes las puntas de flecha de sílex.

Casa de Lara (Villena, Alicante) (29): Tarradell (1969, 15) opinaba que, en ambos casos, la presencia de puntas de flecha de talla bifacial era indicativa de la pervivencia de los mismos durante el Calcolítico, aunque continuaran una tradición anterior.

Arenal de la Virgen (Villena, Alicante) (30): Los problemas que plantean esta yacimiento y el anterior y a los que ya se ha aludido, son los derivados de la existencia de un gran núme- 
ro de referencias al mismo, sin que se hayan publicado los datos completos, o realizado excavaciones de forma sistemática.

La Pastoreta (Alcoy, Alicante) (33): Se encuentra situado a unos centenares de metros de la cueva sepulcral de La Pastoreta y visible únicamente en los materiales existentes en la superficie (Tarradell, 1969, 14).

El Planet (Torremanzanas, Alicante) (38): Tarradell de nuevo se hace eco de la existencia de hallazgos recogiendo informaciones de Belda (Tarradell, 1969, 14), y así señala "indicios de fondos de cabaña circulares, visibles por algunas piedras de muros y tierras negruzcas, con cenizas en su interior». Junto a los fondos de cabaña al parecer existían silos.

\section{B. Silos}

Ante todo, cabe señalar la posibilidad de que algunos de estos yacimientos tengan un carácter sepulcral, tal es el caso de los de Bélgida (Atarcó, Alfogás, Caseta del General), o Villa Filomena (Villarreal) (Bernabéu, 1988, 156), lo que puede deducirse por sus materiales y donde suele aparecer cerámica campaniforme, señalando una cronología algo más tardía. Con todo, se han incluido en el presente catálogo, dado lo poco preciso, en algunas ocasiones, de sus datos.

Villa Filomena (Villarreal, Castellón) (11): Esteve (1956, 543) describe los veintisiete silos de este yacimiento como "sepulcros en forma de silo, originariamente cubiertos por un túmulo». Tarradell $(1961,90)$ plantea las dudas que origina esta interpretación, atendiendo a su forma y cronología y, en relación con los materiales, propugna que sean «silos de habitación" como otros que veremos. Consideramos aceptable la opinión de Tarradell, aunque no deja de ser curiosa la «riqueza» de determinados materiales: 200 cuentas de collar, algunas de piedra verde (variscita?), por ejemplo. Entre las cerámicas halladas figura la campaniforme (Esteve, 1956, 544).

La Comba (Benicassim, Castellón) (12): este posible asentamiento se conoce sólo por las fotografías realizadas por Esteve para la Exposición Internacional de Barcelona de 1929. El propio Tarradell considera dudosa la adscripción (Tarradell, 1963, 107).

Atarcó (Bélgida, Valencia) (20): Es un conjunto de silos de forma cilíndrica, de $1 \mathrm{~m}$. aproximadamente de diámetro y unos $60 \mathrm{~cm}$. de profundidad, salvo el D (Jornet, 1928, 91-92). Además de los descubiertos, el excavador indica que había más por lo que es imposible extraer conclusiones sobre su distribución (Jornet, 1928, 93-94). El D tenía 1,15 m. de profundidad y no era cilíndrico, sino ventrudo, midiendo $1,25 \mathrm{~m}$. en la parte más ancha. En el fondo aparecieron un cráneo y otros restos humanos rodeados por un semicírculo de piedras (Jornet, 1928, 94). Entre los materiales característicos y en varios de los silos se hallaron fragmentos de cerámica campaniforme (Jornet, 1928, 93).

Alfogás (Bélgida, Valencia) (21): En este caso, se localizaron 6 silos de forma y dimensiones idénticas a los de Atarcó. Asimismo, se señaló la presencia de fragmentos de cerámica campaniforme (Jornet, 1928, 95-96). 
Caseta del General (Bélgida, Valencia) (22): Este yacimiento incluye un silo de forma semejante a los de Atarcó con «muchos tiestos rayados por dentro y por fuera de una manera irregular» (Jornet, 1928, 95).

Els Bancalets (Real de Gandía, Valencia) (25): en esta localidad se identificó un sólo silo de 2,60 m. de profundidad, 1,60 × 1,20 m. de ancho en la base y 3,40 × 3,05 m. en la boca. La pared estaba recubierta totalmente por piedras planas (Vidal, 1945, 350). El excavador nos dice que es semejante al del Bancal de la Corona, salvo en que las piedras que recubren las paredes de éste son recientes (Vidal, 1945, 350).

Sifó de les Fanegaes (Albaida, Valencia) (23): este poblado se sitúa como los anteriores en zona llana y está constituido por varios silos de aproximadamente $1 \mathrm{~m}$. de diámetro y unos 70 cms. de profundidad (Ballester, 1946, 21 y Gil Mascarell, 1966, 100-105).

Tabaque (Castellón de Rugat, Valencia) (24): De esta localidad proceden materiales sin que se hayan localizado por el momento las estructuras (Aparicio, Martínez y San Valero, 1977, 53).

La Horteta o Casa Fosca (Potríes, Valencia) (27): este yacimiento ha sido descrito como «sepulturas tumulares» (Aparicio, Martínez y San Valero, 1977, 54). Sólo podemos decir que, en todo caso, sería un poblado situado en llano.

La Barsella (Torremanzanas, Alicante) (39): Próximos al Monte de la Basella, y a lo largo de unos $2 \mathrm{Kms}$. por el centro del valle, con algunas agrupaciones preferentes, se localizaron 70 silos en forma de "campana o cúpula», de unos $2 \times 2 \mathrm{~m}$., excavados en las margas arcillosas (Belda, 1929, 27).

Entre las agrupaciones destaca la del Llano de Santa Ana por su gran número y proximidad, así como también por ofrecer la particularidad de comunicarse entre sí (Belda, 1929, 27).

Figuera Reona (Elche, Alicante) (40): En este yacimiento de la margen derecha del Vinalopó se localizaron «tres fondos de cabaña o vertederos» sin definir de forma clara (Ramos, 1953, 349). Entre sus materiales aparecieron vasos cerámicos lisos y útiles de piedra tallada y pulida. Continuaba posiblemente en la zona de La Rata (Aparicio, Martínez y San Valero, 1977, 60).

Les Jovades-Benatarre (entre Cocentaina y Muro, Alicante) (37): Se hallan en la margen izquierda del río Alcoy y se trata de varias estructuras (tres principales), separadas por sendos barrancos. Están limitados por las sierras de Mariola, Benicadell, Almudaina y Aitana (Pascual, 1986). La relación de los mismos es la siguiente: Pequis, Benatarre, Barranc de Gormaig, La Torreta y Les Jovades en Cocentaina, Carrer Mestre, J. Esteve y L'Almorig en Muro, Horta Major (Alcoy) que aparece citado asimismo como Carrer del Perú, Benilloba, Les Solanetes (Benasau), Balones, Tros de la Bassa (Planes).

Se ubican en tierras llanas, junto a cursos de agua, sobre terrazas más o menos elevadas, o en inmediaciones de tierras pantanosas. En casi todos los casos hay estructuras excavadas en el suelo: 
- Silos o fosas de planta circular y sección generalmente troncocónica con la boca más estrecha que la base, casi siempre plana. Algunos tienen las paredes recubiertas de barro cocido, otros están rellenos de piedras y, en ocasiones, unidos 2 a 2. Las medidas máximas son $1,5 \times 2 \mathrm{~m}$. de diámetro.

- Fosos más profundos que estos primeros, con la boca siempre más amplia que la base que nunca es plana. A veces hay dos juntos, separados por unas distancia de unos $10 \mathrm{~m}$.

Los materiales arqueológiccs consisten en cerámica lisa, peinada y raspada, con algún plato entre las formas que se han determinado, escasos elementos de adorno, puntas de flecha entre las que predominan las de pedúnculo y aletas por lo que respecta a las piezas de sílex, además de numerosos restos de fauna y caracoles terrestres. La extensión de la agrupación de silos de Tros de la Bassa se ha calculado en una 12 Has. por ejemplo. Otro dato interesante es el planteamiento, aún cuando no pueda probarse por el momento, de su sincronismo con las cuevas de enterramiento. El del Carrer del Perú se halla a unos $200 \mathrm{~m}$. de Les Llometes, yacimiento que se ha supuesto podría ser la necrópolis del poblado situado en los alrededores de este fondo de cabaña, el único que se conserva de los de la partida de l'Horta Major (Vicens, 1984, 177). En cualquier caso es difícil determinar el número exacto de los mismos.

Como ya se ha señalado, recientemente Bernabéu $(1988,155-156)$ los ha considerado como pertenecientes al N II de su clasificación.

Camp de San Antoni (Oliva, Valencia) (26): En esta localidad se descubrió un silo de $75 \times 75$ $\mathrm{cm}$. aproximadamente, situado en un terreno llano (Aparicio, Martínez y San Valero, 1977, 55). Entre sus materiales se hallaron algunos fragmentos de campaniforme (Aparicio, Martínez y San Valero, 1977, 55).

La Fonteta de Sarso (Crevillente, Alicante) (41): En un pequeña hondonada se localizaron materiales calcolíticos sin que pudieran identificarse las estructuras (Aparicio, Martínez y San Valero, 1977, 59).

Se conoce asimismo la cita de materiales no funerarios en El Castillo del Río (Aspe, Alicante), La Alcudia (Elche), Ferreginal de la Font Major (Torremanzanas) y Els Dubots (Aparicio, Martínez y San Valero, 1977, 57-60).

\section{Poblados de altura}

Ereta del Castellar (Villafranca del Cid, Castellón) (13): Se considera Calcolítico evolucionado el nivel inferior de este poblado de la Edad del Bronce, defendido por una muralla en su único lugar de acceso fácil (Arnal, Prades y Fletcher, 1968 y Aparicio, Martínez y San Valero, 1977, 48-49). Por otra parte, se señala que, en la base de las estructuras del poblado se encontraron únicamente restos sedimentológicos (Aparicio, Martínez y San Valero, 1977, 49). En principio no hay posibilidad de adscribir ninguna estructura concreta con seguridad a esta fase.

Castillarejo de los Moros (Villar del Arzobispo, Valencia) (14): Se alza este poblado sobre una ladera entre 600 y $650 \mathrm{~m}$. de altitud (Fletcher y Alcacer, 1958, 95). Consta de 7 departa- 
mentos, de los cuales el 1, depósito o concavidad de forma cuadrangular y $1,90 \times 2,10 \mathrm{~m}$., con paredes de piedras irregulares enlucidas (Fletcher y Alcacer, 1958, 78), proporcionó un interesante fragmento de cerámica con decoración de ojos-soles entre líneas quebradas y rectas y escorias de fundición (Martí, 1980, 136), entre otros materiales (Fletcher y Alcacer, 1958, 8).

Esta información es de gran importancia ya que es la más antigua muestra de actividades metalúrgicas, que no de objetos de metal en el área valenciana (Corral, 1986, 226). De confirmarse este extremo podría cambiarse toda la visión que se tiene hasta el momento sobre las primeras actividades metalúrgicas en esta región.

Puntal de la Rambla Castellarda o Mas del Jutge (Lliria, Valencia) (15): Se sitúa a unos 360 m. de altitud sobre el nivel del mar, en un espolón con laderas abruptas al N. y S. (Aparicio, Martínez y San Valero, 1977, 38 y Martínez, 1975, 173). Se habla de la posible existencia de una muralla y dos torreones en su extremo N. W. (Aparicio, Martínez y San Valero, 1977, 40). Asimismo aparecieron muros, posiblemente de habitación) (Aparicio, Martínez y San Valero, 1977, 42). Entre sus materiales se hallaron fragmentos de cerámica campaniforme (Aparicio, Martínez y San Valero, 1977, 44).

El Rincón (Anna, Valencia) (17): En un recoveco entre dos espolones rocosos se localizaron materiales calcolíticos, pero no estructuras (Aparicio, Martínez y San Valero, 1977, 51).

La Muela (Anna, Valencia) (18): Se trata de dos amplias zonas (cabañas I y II), ovaladas, de 10 y $15 \times 8 \mathrm{~m}$., de tierra negra con abundantes cantos rodados y separadas por una distancia de unos $50 \mathrm{~m}$. (Aparicio, Martínez y San Valero, 1977, 52).

Puntal de Carniceros (Villena, Alicante) (31): El cerro escarpado donde se asienta este poblado mide en su zona útil $300 \times 20 / 30 \mathrm{~m}$. La defensa del poblado se completaba con una muralla en su cara E. (Soler, 1981, 67).

Peñón de la Zorra (Villena, Alicante) (32): Es un poblado semejante al anterior, defendido por fuertes escarpes verticales, que se completaban con muros transversales, pero de dimensiones mucho más reducidas $(50 \times 20 \mathrm{~m}$.) (Soler, 1981, 85).

Mola Alta de Serelles (Alcoy, Alicante) (34): Se halla sobre un cerro escarpado en sus vertientes N.E. y S., con un muro de 1'5 m. de espesor y unos 32 de longitud en el lado W. (Botella, 1926, 5). Está formado por grandes bloques de piedra, «careados por uno de sus lados, a dos hileras y rellenado de piedra suelta el intersticio que las mismas dejan entre sín (Botella, 1926, 5). En la parte más elevada (W.) hay una torre circular de $6 \mathrm{~m}$. de diámetro (Botella, 1926, 6).

A partir de esta muralla se organizarían los cinco departamentos conocidos, de planta cuadrangular, que se adaptan al declive del terreno (Botella, 1928, 4). Cada habitación contaba con un banco y un hogar sobre el piso, nivelado con piedras y tierra apisonada (Botella, $1928,4)$. La techumbre la sostenían troncos de madera como el carbonizado que aparece calzado con piedra plana (Botella, 1928, 5). En el extremo $\mathrm{N}$. se cruzan otros dos muros de menor anchura que comunicaban al exterior con un pasillo de entrada mediante una escalera (Botella, 1926, 5). 
Entre los materiales destaca la aparición de un fragmento de cuchillo de cobre y dos moldes de fundición (Botella, 1928, 8-9). El nivel inferior se ha atribuido al H.C.T. o Bronce antiguo.

Mas de Menente (Alcoy, Alicante) (35): Este poblado se alza sobre la ladera de un monte de $830 \mathrm{~m}$. de altitud (Ponsell, 1924-25, 4). Se habla de una muralla (?) de $60 \mathrm{~cm}$. de grosor en la parte más vulnerable, con muros divisorios de $35 \mathrm{~cm}$., todo de piedra y argamasa con un revestimiento interior (Pericot y Ponsell, 1928, 101 y Ponsell, 1924-25).

La forma de las habitaciones, cuadrangulares o trapezoidales, recuerda a las de la Mola Alta de Serelles (Ponsell, 1924-25, 4). Aparecieron unas doce, con unas dimensiones entre $2 \times 3 \mathrm{~m}$. (VII) y $5 \times 4 \mathrm{~m}$. (V) y un hogar semicircular a modo de banco sobre el suelo de arcilla apisonada (Pericot y Ponsell, 1928, 102 y Ponsell, 1924-25, 4).

Entre los materiales, destacan los objetos de metal (un hacha, una sierra y dos puntas de flecha) (Ponsell, 1924-25, 5) y unos "grandes fragmentos de argamasa dura, procedentes, al parecer, de algún horno u hogar» (Ponsell, 1924-25, 8).

Ull del Moro (Alcoy, Alicante) (36): Se halla en una meseta sobre un espolón rocoso. En la ladera sur había un enterramiento (Trelis y Vicens, 1986).

Este yacimiento de la Edad del Bronce puede haber iniciado su vida en el H.C.T. si se tiene en cuenta la presencia de un botón prismático con doble perforación en «V», una punta de flecha con péndulo y aletas y varias láminas de sílex (Vicens, 1984, 189-190).

De sus sistemas constructivos apenas si sabemos que tenía muros de piedra seca sin argamasa (Arribas, 1958, 104-015).

Les Moreres (Crevillente, Alicante) (42): En este yacimiento alicantino se localizó una muralla de 1'90 m. de ancho al S.E. y N., mientras al N.W. aparece un segundo lienzo (González Prats, 1982, 7).

Por lo que respecta a las habitaciones, sabemos que se encontró, sin determinación del nivel, un muro semicircular, de adobe endurecido al fuego con troncos al interior, inclinados hacia la muralla en la que se apoya, de forma ovalada (González Prats, 1982, 7).

En general, se dice que las habitaciones de las fases IV y V son angulares y las de la fase $\mathrm{V}$, sin que se nos especifique su forma, fueron realizadas sobre zócalos de piedra. En todos los casos los muros se revisten de arcilla (González Prats, 1982, 8).

La cronología de la C-14 de la fase VI, última dé habitación, es del $2.210+40$ a.C. (González Prats, 1982, 9). Sería, en consecuencia, la fecha «ante quem» más alta segura conocida para objetos metálicos en el País valenciano, ya que en este asentamiento se ha localizado un cincel de cobre.

En una publicación posterior, González Prats $(1986,89-99)$ atribuye la cabaña que delimitaba al muro adosado a la muralla antes aludido al Calcolítico. De hecho, señala que este poblado es un poblado calcolítico que en un momento dado se fortifica. El material de dicha cabaña se puede considerar sellado y consistía en cerámica con improntas de esterilla, llegando en algún caso hasta el mismo borde, lo cual denotaría un fabricación a molde, en el caso de los grandes vasos, puntas de flecha de base cóncava, de pedúnculo y aletas, hachas de piedra pulida, etc. Hay, asimismo, un escoplo de cobre y una gota, indicio quizá de una actividad metalúrgica local, hecho que no es único como ya hemos visto (González Prats, 1986, 93-94). 
El mismo autor relaciona los materiales con los propios del megalitismo peninsular (platos cerámicos por ejemplo) y en concreto con la zona sur. La cronología que atribuye a la cabaña en función de los citados materiales es del último tercio del III milenio, o a caballo entre el III y el II, aún sin aparecer el campaniforme (González Prats, 1986, 94-98).

Para finalizar debemos reseñar que otros autores (Aparicio, Martínez y San Valero, 1977, 49) citan la posible presencia de un presunto asentamiento calcolítico en Culla (Castellón). ¿Qué rasgos o qué aspectos significativos podemos concluir, una vez finalizada esta relación?

Comenzando por los más generales, podríamos señalar que la evolución temporal muestra una dualidad del hábitat en cueva y al aire libre desde los asentamientos epipaleolíticos, bien es verdad que débil en esos momentos, experimentando una generalización con el paso del tiempo. En los pocos casos concretos que conocemos atribuirles el Postglaciar parece apreciarse una continuidad de ocupación en etapas posteriores, como en los yacimientos de la albufera de Anna o Ferreginal de la Font Major. Y no solamente tal continuidad en sí misma, sino también la preferencia por determinados lugares: de nuevo los yacimientos de la albufera de Anna podrían servir como ejemplo, situados éstos en una laguna, o el del Pinar de Tarruella en las inmediaciones del Arenal de la Virgen en la laguna, desecada en este caso, de Villena, J. Fortea $(1973,155)$ describe esta comarca como un lugar de hábitat privilegiado desde finales del Paleolítico superior, con abundantes yacimientos de diversa tipología y cronología, ubicados tanto en las arenas de fondo lacustre como en las terrazas del Vinalopó, o en las cuevas de las sierras que rodean la laguna.

Por tanto, parece que algunas zonas favorables habrían proporcionado un hábitat adecuado a los distintos grupos humanos, independientemente de su pertenencia a uno u otro momento cultural. No obstante, el hábitat en cueva es el predominante de forma, se puede decir, que absoluta y, posiblemente, en el Paleolítico la situación sería la misma, si bien no estamos en condiciones de perfilar más lo referente a esta estapa. Cabe pensar que las posibilidades de caza, pesca y recoleción, serían buenas para estos grupos humanos no demasiado numerosos, existiendo seguramente, actividades estacionales que deberían ser entendidas en términos de sistemas de yacimientos como se ha puesto de manifiesto para el Paleolítico (Davidson, 1983).

Con el inicio de la economía productora el habitat en cueva es igualmente el más destacado aún cuando conocemos ejemplos más numerosos de poblados de superficie, permitiendo asegurar lo conocido en el resto de la Península que este panorama podría intensificarse. Bien es verdad, desde luego, que la observación resulta de una mayor validez a nivel general que en el caso concreto de la zona valenciana.

No obstante, la posición cronológica de algunos yacimientos es problemática, como lo demuestra la dudosa atribución neolítica de algunos (Pla de la Pitja, Playa del Pinar o Corral Blanc), por ejemplo.

Con todo, los de la albufera de Anna o Salandó podrían pertenecer a la transición de Neolítico, mientras que, en el Arenal de la Virgen y en Casa de Lara, la presencia de cerámica impresa cardial estaría delimitando una ocupación atribuible al primer horizonte neolítico, con lo cual, y según los datos conocidos, los pocos hábitats al aire libre valencianos, se repartirían en los distintos momentos de esta etapa. En estos dos yacimientos se constata, asimis- 
mo, una continuidad con horizontes más tardíos determinados, por ejemplo, por la existencia de puntas de flecha.

Sin embargo, ya hemos visto como las secuencias amplias no se hallan precisamente en poblados de superficie. Recordemos la Cova d'en Pardo (desde el Epipaleolítico microlaminar hasta un enterramiento colectivo por encima de cerámicas esgrafiadas bien fechadas en Les Cendres y fuera de la Península). De la misma manera, en la citada cueva de Les Cendres fundamentalmente, o en la cova de l'Or puede verse igualmente la transición del Neolítico al Eneolítico. Con todo, ni estas ni la de Ereta son estratigrafías tan amplias como la de en Pardo.

Es decir, únicamente un yacimiento ofrece toda la secuencia que contemplamos en el presente artículo y se trata de una cueva, lo cual viene a reforzar lo ya indicado por alguno de nosotros, así como lo que evidencian los materiales: los yacimientos de superficie presentan ocupaciones cortas en contraste con los otros, al menos hasta el Eneolítico.

Algunos de los yacimientos eneolíticos, ofrecen ocupaciones de los momentos de transición al Bronce, como sucede en la Ereta, pero también se da el caso de poblados que desarrollan su vida pricipalmente en este segundo momento, pudiendo señalarse, a veces con dudas, un nivel inferior perteneciente al primero (Ereta del Castellar, Les Moreres, Castillarejo de los Moros, Ull del Moro, etc.,). Incluso el horizonte eneolítico no tiene por que ser el mismo. Algunos de ellos, proporcionan cerámica campaniforme, indicadora según algunos autores de un Calcolítico en sentido estricto, ésto es de la aparición de la metalurgia (Beniprí, Villa Filomena, o algunos de los de Bélgida). Este extremo podría verse modificado de todas formas por lo que a las actividades metalúrgicas se refiere. Sin embargo, los denominados silos ofrecen ocupaciones bastante puntuales, lo que desde luego estaría de acuerdo con la supuesta utilización funeraria de algunos de ellos, donde la presencia, además de campaniforme, nos llevaría al enterramiento individual.

De todos modos, la mayoría de los yacimientos de los distintos momentos estudiados son conocidos exclusivamente por prospecciones y recogidas superficiales. Ello nos priva, por tanto, de conocer la extensión real de los mismos, o la verdadera funcionalidad de algunos (los de Bélgida, o Villa Filomena, o el hallazgo neolítico de Villarreal).

Podríamos resumir lo dicho señalando que si bien algunas áreas parecen presentar una amplia continuidad en la ocupación, no sucede lo mismo con los yacimientos, al menos al aire libre, salvo excepciones. No parece existir una secuencia clara sobre todo desde el neolítico hasta la Edad del Bronce inclusive, posiblemente porque quizá sea en esas etapas cuando más se diversifica el tipo de hábitat.

Por lo que respecta a la distribución geográfica, cabe señalar que interesaría el estudio de los yacimientos en relación con su entorno y entre ellos mismos, lo que no ha sido posible realizar aquí por las razones ya expuestas. Todo lo indicado y lo que señalaremos a continuación está condicionado por la posible pérdida de información y está a expensas de lo que probablemente puedan aportar futuras prospecciones. Desde luego, la mayor concentración de yacimientos absolutamente hablando, se detecta al sur del Júcar, entre las cuencas de los ríos Vinalopó y Serpis. Los yacimientos de la provincia de Castellón son escasos y dudosos en el caso de los neolíticos. Pero la mayor densidad en la zona indicada vendría a reforzar 
la idea ya expuesta de continuidad de habitación en áreas favorables al asentamiento, como las ya señaladas.

En esta misma zona se encuentran algunas de las cuevas más destacadas (Mallaetes, Sarsa y Or), en cuyas estratigrafías se constata una ocupación desde el Paleolítico (Mallaetes o Parpalló, por ejemplo), quedando, sin embargo, más al norte el poblado de la Ereta.

Por lo que respecta a los restos de construcciones, no podemos decir que los yacimientos hayan sido excesivamente pródigos. De los yacimientos neolíticos solamente se puede citar la presencia de fondos de cabaña o fondos de Les Santes o El Tirao en un número bastante escaso ( 1 en el primero de ellos y 5 en el segundo, de los cuales el único estudiado tenía una planta circular). Casa de Lara conserva improntas de troncos y cañas de una supuesta armazón y prácticamente nada más.

De los poblados calcolíticos en llano sólo se ha calculado de forma aproximada la extensión de dos de ellos: Ereta del Pedregal unas 6 Has. y La Macolla $1 \mathrm{Ha}$. El primero de ellos además ocupa un altozano sobre el posible lecho del lago y el segundo se halla en la laguna de Villena. El Planet o Beniprí parecen ser fondos de cabaña, acompañados por silos en el primer caso. La Ereta podría ser interesante para completar la evolución de las estructuras, pero recordemos brevemente los datos existentes. Del nivel I no se tiene conocimiento de la forma de las mismas, aunque sí de la existencia de conjuntos de piedras y restos de barro cocido. Del II se conocen pavimentos entre fragmentos de muros formados por lajas hincadas verticalmente y rellenas de piedras y barro. Por último, del III se conoce la aparición de un muro de piedras en hiladas regulares, supuesta muralla del poblado. No tenemos ninguna precisión en los detalles que nos sirva de ayuda.

Es más difícil establecer ninguna conclusión a partir de los llamados silos, dadas las dudas existentes en cuanto a su funcionalidad. Por otro lado, sus dimensiones tampoco abogan por su utilización como hábitat (1, 1'25 ó incluso $2 \mathrm{~m}$.). Se caracterizan por su situación en llano, su gran número y cercanía, además de comunicarse entre sí, en alguno casos. En alguna ocasión, han sido descritos también como vertederos. Se hallan próximos a cursos de agua o cerca de zonas pantanosas algunos de ellos. En Tros de la Bassa se ha calculado una extensión de unas 12 Has para todo el conjunto.

Entre los pobladores de altura, únicamente seis proporcionan datos más seguros. Cuatro de ellos se defienden mediante murallas, pero sólo tres tienen además defensas naturales. La coincidencia de datos sobre casas y estructuras defensivas es reducida, ya que sólo en dos de ellos se hallaron ambos elementos. Las murallas pertenecen ya a la Edad del Bronce como puede verse en la Ereta del Castellar, Les Moreres, Puntal de Carniceros, Mola Alta de Serelles y quizá Mas de Menente y Puntal de la Rambla Castellarda.

La forma de las habitaciones varía: una cabaña ovalada con un muro semicircular de adobe endurecido a fuego con troncos en el interior en Les Moreres, una cuadrangular en Castillarejo de los Moros, o bien fondos de cabaña ovalados, de tierra negra con cantos rodados en La Muela. Las estructuras, como puede verse, no tienen demasiada consistencia. Por otra parte y salvo excepciones, es difícil adscribirlas con seguridad a los distintos niveles y se supone la ocupación eneolítica más bien en función de los materiales.

Pero veamos otro aspecto importante que sin duda influyó en los cambios que se eviden- 
cian en el asentamiento: el medio ambiente. Según los datos proporcionados por la sedimentología y los análisis de polen, parece ser que en el período Holoceno, en la zona mediterránea peninsular, hay una vegetación abierta que indica un régimen climático contrastado o marcadamente seco, con precipitaciones fuertes y esporádicas que provocó una denudación de las laderas bajo la acción de las arroyadas. Pinus sigue conservando una cierta importancia, entrando en competencia con Quercus T. faginea o T. ilex-coccifera, por la que se verá sustituido (Dupré 1988, 145).

Este ambiente perdura en en Neolítico incial aún cuando se hace progresivamente más templado. A firales del mismo período o principios del medio, se llega a un régimen de precipitaciones regular o bien repartido a lo largo del año, lo que permite regenerar la cobertura vegetal. En los ambientes adecuados se favorece la extensión del medio lagunar. Ello tiene lugar en el período Atlántico (Fumanal, 1986, 197-198). Para este mismo momento los datos de Cova de l'Or indican un paisaje abierto, con pocos pinos y los alrededores de la cueva totalmente deforestados por el hombre agricultor o ganadero con el objeto de disponer de terrenos, obtenidos mediante el incendio. La deforestación y la presencia de cereales se constratan asimismo en la Sarsa (López, 1986, 143-158).

En el IV milenio hay un cambio hacia rasgos más áridos y estacionales. El bosque mediterráneo deja lugar, paulatinamente, a un paisaje abierto y degradable a causa de la acción antrópica, especialmente cerca de los hábitats. Los pinos más alejados y situados en las laderas menos fértiles viven mejor. En el Neolítico final (Calcolítico ?) se reactiva el proceso, lo cual coincide con la ocupación de La Ereta. Durante el Eneolítico se instala en los alrededores de este yacimiento, fuera de las zonas de cultivo, un herbazal con predominio de la cicoráceas. Este paisaje abierto, con pinos diseminados y algunos caducifolios refugiados en zonas de cierta humedad edáfica y no trabajadas, es el que, en la zona valenciana, rodea las áreas habitadas (Fumanal, 1986, 198-199).

En el período Subboreal del polen, la erosión provoca un continuo relleno del espacio lagunar, lo que facilita la instalación humana. Lo mismo se registra en los espacios albufereños como la Marjal de Pego, que se rellenan y permiten el asentamiento de poblados del Bronce en un área antes sumergida (Fumanal, 1986, 198-199).

Parece entonces muy probable que este panorama sea al tiempo una de las causas y consecuencia a su vez de la acción del hombre. Ya hemos señalado la continuidad y densidad de ocupación en lugares concretos, entre ellos las lagunas, abundantes en el área valenciana, que supondrían zonas con un potencial de recursos importante de cara a la obtención de alimentos. Los yacimientos en cueva tal como alguno de nosotros ha constatado (Rubio, 1981 y 1988), han proporcionado abundantes vestigios de agricultura y domesticación de animales. Ello se complementa con los datos procedentes de análisis polínicos, así como la constatación de la acción del hombre sobre el medio ambiente con el fin de disponer de terrenos para las nuevas actividades económicas del Neolítico. Por tanto, paralelamente al desarrollo lagunar que potenciaría los recursos ya existentes, se intensificarán los trabajos encaminados a una mejora en la agricultura y la ganadería. La cueva, abundante en estas áreas donde asimismo se documentan las mayores densidades de yacimientos, ofrece un hábitat seguro y ninguna dificultad o escasas, al parecer, para desarrollar las labores citadas: se utiliza el terre- 
no mismo que las rodea. No es posible, por desgracia y para este momento, conocer si existe una diferente funcionalidad para el hábitat de superficie.

Si como señala Martí $(1985,67)$ el hábitat en cueva supone un escaso crecimiento demográfico, habría que pensar que su predominio patente en los datos conocidos se debe a la existencia de sociedades con bajo número de habitantes que fundamentalmente, intensifican pautas alimenticias anteriores, a pesar de conocer ya la producción de alimentos, hecho que estaría en concordancia con la importancia de la caza en el horizonte cardial, por ejemplo, y quizá (sólo podemos suponerlo) de las especies vegetales no cultivadas o de la pesca. Estas actividades van a irse equilibrando hasta complementarse en cuanto al papel jugado en la economía en el Neolítico pleno, para decantarse finalmente por el predominio de la agricultura y la ganadería (Rubio, 1988).

En el llamado Neolítico final (transición al Eneolítico o incluso Eneolítico de otras sistematizaciones) visto en la Ereta, por ejemplo, parece que la degradación del entorno de los hábitats habría llegado a su punto culminante principalmente alrededor de los mismos. Varios son los aspectos que cabe resaltar. Por un lado, el relleno de las lagunas amplia el espacio que se puede destinar al hábitat, pero por otro, hay que tener en cuenta la eliminación de determinados recursos que ciertamente ya no serán excesivamente necesarios, o lo serán en ocasiones muy concretas merced al desarrollo de la economía de producción. El hábitat parece desplazarse sobre todo a los poblados a aire libre, muchas de cuyas ocupaciones se inician ahora. ¿Supone eso una paulatina adopción del hábitat de superficie causada por un crecimiento demográfico? ¿Estaría facilitado éste por una intensificación de la agricultura y la ganadería? Recordemos que Bernabéu $(1988,56)$ había sugerido para este momento una modificación de la tecnología agrícola que incorporaba el arado, los animales de tracción y la utilización del agua a pequeña escala. En este sentido, podemos decir que, en los momentos finales del Neolítico, en sentido estricto, habíamos constatado ya la sustitución del predominio de los ovicápridos por el cerdo y la vaca, por lo que respecta a los animales domésticos (Rubio, 1988). Quizá, efectivamente, habría una diversificación de estas especies pensando no sólo en la alimentación, sino en su utilización como animales de tiro o para otras industrias. Podrian haberse necesitado además, nuevas tierras por agotamiento e insuficiencia de las que rodeaban las cuevas anteriormente ocupadas, o bien su sustitución por otras más cercanas a los nuevos hábitats. En cualquier caso, estaríamos hablando ya de sociedades campesinas propiamente dichas, ésto es, con una economía basada fundamentalmente en la agricultura y en la ganadería. Desgraciadamente los datos sobre estas actividades o sobre el comercio, provenientes de los yacimientos Eneolíticos de esta zona son escasos y no permiten extraer demasiadas conclusiones para este momento preciso. Sin embargo, en otras áreas peninsulares cabe hablar ahora de diversificación de las especies cultivadas, por ejemplo, así como de la aparición de determinadas industrias derivadas de la economía productora.

Por lo que respecta a la metalurgia se ha hecho ya alusión a la escasa presencia de objetos de cobre o de actividades metalúrgicas en estos yacimientos (Les Moreres o Castillarejos de los Moros) (Corral, 1986, 225-226), y su generalización en cambio en el H.C.T. a fines del III milenio, ligada ya al vaso campaniforme. Por tanto, las transformaciones operadas en este momento, realmente no parecen poderse atribuir a la aparición de esta nueva actividad que, 
por otra parte, parece ofrecer pocas posibilidades en este área en cuanto a los potenciales recursos mineros (Corral, 1986, 15-16) y sí en cambio a las razones expuestas anteriormente, puesto que la tendencia se ha iniciado ya antes de la constatación de la escasa actividad metalúrgica, lo que por otra parte, sucede en casi todo el Eneolítico europeo, salvo focos concretos.

El País valenciano ve aparecer el rito de inhumación colectiva, pero, sin embargo, no la presencia de megalitos o incluso de cuevas artificales presentes en otras áreas cercanas. $\mathrm{Da}$ la sensación que la inversión de energía y esfuerzo que se ha llevado a cabo en las construcciones del hábitat, ésto es en el ámbito de lo doméstico, no ha tenido su correspondencia en el mundo funerario, para el que se empleaban las mismas cuevas naturales. ¿Se trata de grupos humanos que no pueden permitirse este tipo de inversión? ¿O más bien que no resulta necesario reforzar la cohesión entre los miembros de esta sociedad porque la competencia por las tierras no lleva a enfrentamientos? Posiblemente, si hubo un empleo de agua a escala reducida como señala Bernabéu el dominio sobre la misma tampoco sería vital, ya que la aridez tampoco parece haber sido demasiado importante, desde luego no como en el S.E., aún cuando los ragos estacionales se hicieran más marcados como indican los diversos análisis. Recordemos cómo la aparición de dispositivos de defensa en los poblados no se produce hasta la Edad del Bronce. Por otro lado, quizá el crecimiento demográfico no fuera tampoco tan espectacular como para ocasionarse una competencia marcada por los recursos. No obstante, los poblados eneolíticos no evidencia nunca unas construcciones demasiado importantes, por lo que da la sensación de que no serían más que aldeas campesinas, pertenecienes a grupos con escasa complejidad social e incluso económica.

Por tanto, la generalización de la metalurgia iría unida a la presencia del campaniforme y también al rito de inhumación individual. La fortificación de los poblados eneolíticos en la Edad del Bronce sí evidencian una importante inversión de esfuerzo y de orden económico en general en los asentamientos, si bien en este caso en respuesta seguramente a otra estructuración y motivaciones de la sociedad, cuyos carácteres serán posiblemente una intensificaciń de pautas ya esbozadas en el Eneolítico más que cambios radicales. Con todo, parece manifestarse una organización social diversa que permite dedicar gente y recursos a la construcción de muros defensivos, y posiblemente, una nueva mayor competencia entre los grupos que los hace necesarios, así como una mayor repercusión de la metalurgia en la economía.

Para concluir nos resta únicamente señalar que las expuestas con una serie de observaciones hechas en un primer acercamiento al tema y que algunas necesitarían de la consideración de otros datos con los que, por el momento, no contamos, o con la profundización en determinados aspectos que no nos ha sido posible realizar. Con todo, las pautas que se ponen en manifiesto en esta secuencia son lo suficientemente sugerentes como para hacernos pensar que futuras investigaciones pueden resultar de gran interés para el conocimiento de los procesos del cambio cultural de la prehistoria peninsular. 


\section{BIBLIOGRAFIA}

ADAMS, R. M. (1966): The evolution of urban society, Chicago.

ALCACER, J. (1958): "El Castillarejo de los Moros (Andilla, Valencia)", Archivo de Prehistoria Levantina VIII, 93 y ss.

APARICIO, J. (1975): «Los yacimientos prehistóricos de la albufera de Anna (Valencia)», XIII C.A.N., Zaragoza, 191-198.

- MARTínez, J. y SAN VAleRo, J. (1977): «El puntal sobre la rambla Castellarda y el poblamiento Eneolítico de la Región Valenciana", Saitabi XXVII, 37-62.

ARnAl, J., PRADes, H y FleTCHeR, D. (1968): La Ereta del Castellar (Villafranca del Cid, Castellón), S.I.P. 35.

ARRIBAS, A. (1959): "El urbanismo peninsular durante el Bronce primitivo", Zephyrus X, 81 y ss.

BADAL, E, y GGRAU, E. (1986): "El paisaje vegetal eneolítico de la comarca valenciana de La Safor, a través del análisis antracológico», El Eneolítico en el País Valenciano, 35-42.

BALleSter, I. (1946): «Sobre prehistoria albaidense», Archivo de Prehistoria Levantina II, 331 y ss.

BELDA, J. (1929): “Excavaciones en el Monte de Barsella, término de Torremanzanas», M.J.S.E.A. 100.

BERNABEÚ, J. (1986): «El Eneolítico valenciano: ¿Horizonte cultural o cronológico?», El Eneolítico en el País Valenciano, 9-14.

- (1988): «El Neolítico» en las comarcas meridionales del País Valenciano», LÓPEZ, P. (Coord.): El Neolítico en España, 131-166.

Botrlla, E. (1924-25): «Excavaciones en la Mola Alta de Serelles (Alcoy, Alicante)», M.J.S.E.A., 79.

- (1927): "Excavaciones en la Mola Alta de Serelles (Alcoy - Alicante)», M.J.S.E.A., 94.

BRAIDWOOD, R. J. y WILLEY, G. R. (Eds.) (1962): Courses towards urban life, Chicago.

BRUMFIEL, E. M. y EARLe, T. K. (Eds.) (1987): Specialization, exchange and complex societies, Cambridge.

CARNEIRO, R. (1970): "A theory of the origin of the State", Science 169: 733.

CORRAL, M. (1984): El Bronce medio de la Meseta inferior y sus relaciones con otras áreas peninsulares (Aspectos socio-económicos),Tesis doctoral inédita, Universidad Autónoma de Madrid.

- (1986 a): «Actividades comunitarias y privadas durante las edades del Metal. Un ejemplo: la metalurgia", Arqueología especial 8, Teruel, 219-233.

- (1986 b): «Las primeras actividades metalúrgicas y su desarrollo en el País Valenciano", El Eneolítico en el País Valenciano, 15-21.

CUENCA, A. y WALKer, M. (1986): "Aspectos paleoclimáticos'del Eneolítico alicantino», El Eneolítico en el País Valenciano, 43-49.

DAVIDSON, I. (1983): «Site variability and prehistoric economy in Levante», BAILEY, G. (Ed.): Huntergatherer economy in prehistory, Cambridge, 79-95.

DUPRE, M. (1988): Palinología y Paleoambiente, S.I.P. Valencia.

ESTEVE, F. (1944): «Estación neolítica de Les Santes (Cabanes, Castellón), Saitabi 11, 31-33.

- (1956): "Cerámica de cuerdas en la Plana de Castellón», C.I.C.P.P. IV, 543-556.

Fletcher, D. (1961): "La Ereta del Pedregal (Navarrés, Valencia)», Archivo de Prehistoria Levantina IX, 79-96.

- Pla, E. y Llobregat, E. (1965): «La Ereta del Pedregal (Navarrés, Valencia)», Excavaciones Arqueológicas en España 42.

FORTEA, J. (1973): Los complejos microlaminares y geométricos del Epipaleolítico mediterráneo español, Universidad de Salamanca.

FRIED, M. (1967): The Evolution of political society, New York.

FRIEDMAN, J. y ROWLANDS, M. Q. (Eds.) (1978): "The Evolution of social systems", American Antiquity. 
Fumanal, M. ${ }^{a}$ P. (1986): Sedimentologia y clima en el País Valenciano, S.I.P. 83, Valencia.

GIL MasCarell, M. (1966): "Yacimientos del valle de Albaida (Valencia)» IX C.A.N., Zaragoza, 100-105.

Gilman,A. (1987 a): "Unequal development in Copper Age Iberia», BRUMfiel, E. M. y EARLE, T. K.

(Eds.), Specialization, exchange and complex societies, 22-29.

- (1987 b): «El análisis de clase en la Prehistoria del S.E.», Trabajos de Prebistoria 44, 27-34.

- y THORNes, J. B. (1985): Land use and Prehistory in Southeast Spain, Londres.

GODELIER, M. (1971): Esquemas de evolución de las sociedades. Madrid.

González Prats, A. (1982): «Peña Negra. Prehistoria y Protohistoria de la Sierra de Crevillente (Alicante)", Revista de Arqueología 28, 6 y ss.

- (1986): «El poblado calcolítico de Les Moreres en la Sierra de Crevillente», El Eneolítico en el País Valenciano, 89-99.

GORDON CHILDE V. (1954): Los orígenes de la civilización, México.

- (1976): Nacimiento de las sociedades orientales, Barcelona.

JORnet, M. (1928): "Prehistoria de Bélgida», Arcbivo de Prebistoria Levantina I, 91-99.

LÓPEZ, P. (1978): «Resultados polínicos del Holoceno en la Península Ibérica», Trabajos de Prebistoria 35, 9-44.

- (1986): «Estudio palinológico del Holoceno español a través del análisis de yacimientos arqueológicos", Trabajos de Prebistoria, 43, 143-158.

ManZanilla, L. (Ed.) (1987): Studies in the neolithic and urban revolutions, México.

MARTí, B. (1980): «El Eneolítico", Nuestra Historia, 125 y ss.

- (1985): "Los estudios sobre el Neolitico en el País Valenciano y áreas próximas", Arqueología del País Valenciano: panorama y perspectivas, 53-84.

Martínez Perona, J. V. (1975): "Carta arqueológica de Pedralba y Bugarra», Archivo de Prehistoria Levantina XIV, 173 y ss.

MESADO, N. (1970): «Yacimientos arqueológicos de Burriana (Castellón)», Archivo de Prebistoria Levantina XII, 177-204.

MuÑoz, A. M. ${ }^{a}$ (1985): «El Eneolítico en el País Valenciano y Murcia», Arqueología del País Valenciano: Panorama y perspectivas, 85-99.

OlARIA, C. (1980): «Aportación al conocimiento de los asentamientos neolíticos en la provincia de Castellón", Cuadernos de Prehistoria y Arqueología Castellonense 7, 31-87.

- (1988): «El Neolítico en las comarcas castellonenses», LÓPEZ, P. (Coord.): El Neolítico en España, $101-130$.

PASCUAL, J. L. (1986): «Les Jovades (Cocentaina). Notes per l'estudi del poblament eneolitic a la conca del Riu d'Alcoi», El Eneolítico del País Valenciano, 73-87.

Pericơ, L. y PONSEll, F. (1928): «El poblado de Mas de Menete (Alcoy, Alicante)», Archivo de Prehistoria Levantina I, 109 y ss.

Pla, E. y Martí, B. (1983): «La Ereta del Pedregal (Navarrés, Valencia) y los inicios de la Edad del Bronce», XVI C.A.N., 239 y ss.

- y Bernabeu, J. (1983): «Ereta del Pedregal (Navarrés, Valencia). Campañas de excavación (1976-79)», Noticiario Arqueológico Hispano 15, 39 y ss.

PONSEll, F. (1924-25): «Excavaciones en la finca Mas de Menente, término de Alcoy (Alicante)», M.J.S.E.A., 78.

Ramos, A. (1953): "Mapa Arqueológico de Elche», Archivo español de Arqueología XXVI, 346 y ss.

RAMOS, A. (1980): «Interpretación de las secuencias culturales de la Edad del Cobre en la zona meridional de la Península Ibérica. La alternativa de materialismo cultural», Cuadernos de Prehistoria. de la Universidad de Granada 5, 203 y ss.

RUBIO, I. (1981): Aspectos socio-económicos del neolítico peninsular, Tesis doctoral inédita, Universidad Autónoma de Madrid.

- (1981-82): «Enterramientos neolíticos de la Península Ibérica» CuPAUAM 7-8, 39-73.

- (1984-85): «En torno a la problemática del hábitat al aire libre en el neolítico peninsular», $C u$ PAUAM 11-12, 153-161. 
- (1988): «La Economía de subsistencia en el neolítico hispano», LÓPEZ, P. (Coord): El Neolítico en España, 337-418.

SABlOFF, J. A. y LAMBERG-KARLOVSKY, C. C. (Eds.) (1974): The rise and fall of civilizations: selected readings, California.

SERVICE, E. R. (1984): Los orígenes del Estado y de la civilización, Madrid.

SOLER, J. M. ${ }^{\text {a }}$ (1976): Villena. Prebistoria-Historia-Monumentos, Alicante.

- (1981): El Eneolítico en Villena, S. A. 7, Valencia.

TAINTER, J. A. (1988): The Collapse of complex societies, Cambridge.

TARRADELL, M. (1961): «Sobre la identificación de los poblados eneolíticos valencianos», VI C.A.N., 89-91.

- (1963): El País Valenciano del Eneolitico a la Iberización, A.U.V. XXXVI, Valencia.

- (1969): «La cultura del Bronce valenciano. Nuevo ensayo de aproximación», Papeles del Laboratorio de Arqueología de Valencia 6, 7 y ss.

Trelis, J. y VICENS, J. (1986): «El Eneolítico en Alcoy: Bases para su estudio», El Eneolítico en el País Valenciano, 101-110.

UCKo, P. J., Tringham, R. y Dimbleby, G. W. (Eds.) (1972): Man, settlement and urbanism, Londres.

VICENS, J. (1984): «Eneolítico", Alcoy. Prehistoria y Arqueología. Cien años de investigación, 175-193.

VICENT, J. M. (1989): Bases teórico-metodológicas para el estudio del comienzo de la metalurgia en la Península Ibérica, Tesis doctoral inédita, Universidad Autónoma de Madrid.

VIDAL, V. (1945): «Els Bancalets», Arcbivo de Prehistoria Levantina, II, 350.

VISEDO, C. (1925-57): «Breu noticia sobre les primers Edats del Metal a les proximitats de Alcoy», B.A.C.A.E.P. VIII, II, 173-176.

WiTtFoGel, K. A. (1966): Despotismo oriental. Un estudio comparativo del poder totalitario, Madrid. 